\title{
Comparison Between The Efficacy and Safety of The Single- (Love Baby) and Double-Balloon Catheters for Cervical Ripening and Labor Induction
}

\section{Meng Hou}

Xi'an Jiaotong University https://orcid.org/0000-0002-6510-886X

\section{Weihong Wang}

Xi'an Jiaotong University Medical College First Affiliated Hospital

Dan Liu

Xi'an Jiaotong University Medical College First Affiliated Hospital

Xuelan Li ( $\square$ lixuelan2020@163.com )

Xi'an Jiaotong University Medical College First Affiliated Hospital

Research article

Keywords: cervix, balloon catheters, single- and double-balloon catheters, labor induction, cervical ripening

Posted Date: July 16th, 2020

DOl: https://doi.org/10.21203/rs.3.rs-37246/v1

License: (c) (i) This work is licensed under a Creative Commons Attribution 4.0 International License. Read Full License 


\section{Abstract}

Background: Induced labor is a progressively common obstetric procedure, Whether the specifically designed double-balloon catheter is better than the single-balloon device in terms of efficacy, efficiency and safety yet remains controversial.

Methods: In our study We have performed a Retrospective study in which 220 patients with immature cervix were admitted for induction of labor either through single cervix balloon catheter (love-baby) (SBC) or double cervix balloon catheter (DBC). The comparison showed that the cervical bishop score was slightly higher for the SBC after removal or expulsion of the balloon.

Results: This was a proof that SBC demonstrates slightly better efficacy for cervical ripening with a shorter time from balloon placement to spontaneous vaginal delivery than DBC. No significant differences in the comparison between SBC and DBC following other parameters like spontaneous vaginal delivery, the initiate uterine contractions rate, the number of patients that needed oxytocin, the balloon spontaneous expulsion rate and others have been detected. Interestingly, SCB showed a higher incidence in adverse reactions leading to taking out the balloon halfway. The multi-factor analysis showed that the spontaneous labor was a risk factor for the cesarean section in SBC patients.

Conclusion: These results prove that the new Chinese single balloon, also called love baby, can effectively induce labor as it may be highly recommendable for cervical ripening than $\mathrm{DBC}$, though it could be with a higher incidence of adverse reactions causing the balloon to be pulled out halfway.

\section{Background}

The induced labor is defined as the use of drugs and/or machinery to induce uterine contractions before spontaneous delivery and start of labor and to achieve vaginal delivery. Many conditions lead to an induced labor. Among them are the delayed and prolonged pregnancy (more than 41 weeks), some maternal severe complications like gestational hypertension, gestational diabetes mellitus, kidney disease, etc. All require preterm termination of pregnancy in an assisted manner. Often, fetal factors exert pregnancy termination and they include fetal growth restriction (FGR), stillbirth, severe fetal malformation, fetal appurtenances factors such as oligohydramnios, premature rupture of membranes, and poor placental function, which also requires induced labor. It has reported that about $15 \%$ to $30 \%$ of all pregnancies require induced labor $(1,2)$. Over the past decades, the incidence of childbirth induction has been increasing.

Cervical maturity is the decisive factor for the success of the induced labor. At present, there are many methods to promote cervical ripening, one of which is the disposable cervix balloon catheter which is made of silica gel. It provides stable and mild mechanical stimulation to the cervix, inducing it to soften, ripe and make uterine contractions in order to accelerate the progress of childbirth(2). For the purpose, the cervix balloon is currently widely used in clinical practice. Many studies refer to the use of the simple cervical balloon, which is made from Foley catheter and is filled with about $30-60 \mathrm{ml}$ of water(3). The 
modification of the simple balloon that we report here (also called love-baby) differs from the common simple balloon. The SBC modification, called love-baby, was independently developed and produced in China, with the modification in which the intrauterine balloon was filled with $150 \mathrm{ml}$ of water. There have been few reports of this Chinese new type of single balloon catheter (SBC love-baby). In this study, we first reported the detailed comparison by efficacy and safety between this new single-balloon catheter and the COOK - the double-balloon catheter (DBC) in the process of ripening the cervix and inducing labor. We have also provided a relatively reliable guidance for clinical practice .

\section{Methods}

\subsection{Patients' information and clinical data}

The study is a retrospective study spanning between January, 2017 and November, 2019 in the First Affiliated Hospital of Xi'an Jiaotong University, Shannxi, China. In the study We split 220 pregnant women with term pregnancy who induced labor into two groups based on the use of single- or double balloon catheter.Both groups (SBC and DBC) encompassed 110 cases each. In SBC device the uterine balloon is one. The type called "love baby" SBC was produced by Jiangsu Aiyuan Medical Technology Co., Ltd (model: AY-K-1). The DBC had two balloons: one uterine balloon and one vaginal balloon. The brand of DBC was produced by COOK Medical Technology Co., Ltd and here, we designate it as COOK DBC. Both balloons were made of silica gel. Pictures of the two types of cervical balloons are shown in Figure 1.

\subsection{Applied research method}

All 220 pregnant women had indication for assisted induction of labor. The inclusion criteria included: (1) singleton pregnancy; (2) cephalic presentation; (3) full - term pregnancy ( $\geq 37$ weeks); (4) intact fetal membrane; (5) cervical Bishop score $\leq 6$; (6) no other contra-indications for vaginal delivery.

The exclusion criteria included: (1) a previous cesarean section or hysteromyomectomy; (2) placenta or prevascularization; (3) cephalopelvic disproportion and abnormal birth canal; (4) severe pregnancy complications which could not tolerate vaginal delivery; (5) infectious diseases of the reproductive tract; (6) obvious fetal distress; (7) allergy to silica gel. Patients underwent vaginal micro ecological, pelvic ultrasound, fetal heart monitoring and vaginal examinations.

\subsection{Indicator factors used for comparison between SBC and DBC}

The indicators used for comparison between the SBC and DBC induced childbirth included changes in cervical bishop score before and after the use of the balloon, vaginal delivery rate, caesarian section birth rate, vaginal delivery rate within 24 hours, time from balloon placement to spontaneous delivery, balloon shedding rate, incidence of premature rupture of membranes, amniotic fluid contamination rate, neonatal Apgar score, etc. In the two groups we have observed the incidence of adverse events, including vaginal bleeding, uterine contraction, discomfort, postpartum hemorrhage, fever, etc.

\subsection{Statistical methods}


All data were statistically analyzed in SPSS 22.0. The measurement data were expressed by mean values \pm standard deviation (median and rang). The comparison between the two groups was tested by independent $t$ test or the Mann-Whitney $U$ test (in the case of abnormally distributed variables). The counting data were expressed by $\mathrm{n}(\%)$ and compared by application of the Continuity Correction or Fisher's Exact Test when warranted. Furthermore, the univadate $x 2$ test and multivariate logistic regression model were used in the analysis of cesarean section related factors $₫$ At $P$ values $\leq 0.05$, the data were accepted as statistically significant.

\section{Results}

\subsection{Demographic data and factors leading to induced labor}

The SBC group of patients included 110 pregnant women with an average age of $28.736 \pm 3.639$ years old. The mean number of pregnancy weeks was $39.838 \pm 1.053$ weeks. Among all patients, 89 (accounting for $80.9 \%)$ were primipara while $21(19.1 \%)$ of the patients were multipara. There were 110 pregnant women in DBC group, the mean age of the patients was $29.35 \pm 3.598$ years old, the median pregnancy week was $40.066 \pm 1.061$ weeks. 8 of the patients $(77.27 \%)$ were primipara while $26(22.73 \%)$ patients were multipara. There was no significant difference in age, gestational week, parity $(P=0.257$;MannWhitney), ( $(p=0.373 ; X 2=0.794),(p=0.068 ;$ Mann-Whitney), respectively. All these data are summarized in Table 1.

The clinical diagnoses and medical data leading to the decision of induced labor in both groups are presented in Figure 2. In the SBC group diagnoses like oligohydramnios accounted for $43.6 \%$, delayed pregnancy for $18.18 \%$, while suspected fetal distress accounted for $8.18 \%$ only. In DBC group, these parameters were oligohydramnios (40\%), delayed pregnancy (35.45\%) and gestational diabetes mellitus (16.36\%).

\subsection{Delivery outcome and related obstetric parameters}

Next, we have analyzed several other parameters in the two groups like the delivery outcome and other related obstetric parameters. These data are summarized in Table 2. Studying the difference in the vaginal delivery rate between the two groups showed no statistical significance. The vaginal delivery rate was $60.9 \%$ for SBC versus $58.18 \%$ for DBC while the cesarean section rate was $39.1 \%$ for SBC and $41.82 \%$ for DBC. In SBC group, the cervical bishop score was $3.664 \pm 1.416$ before the balloon was placed and $6.418 \pm 1.511$ after its removal off the cervix or its natural falling off. In the DBC group, the cervical bishop score was $3.355 \pm 1.324$ before the balloon was placed, and $5.473 \pm 1.618$ after its natural or assisted removal. The statistical analysis showed that there is a significant difference on this parameter between the two groups. The difference in the Bishop score after removal of the cervix balloon or its spontaneous falling off between SBC and DBC groups was statistically significant with $\mathrm{P}<0.0001$, assessed by the Mann-Whitney test. The detected increase in the Bishop score between the two groups, i.e. $2.755 \pm 1.746$ for $S B C$ versus $2.109 \pm 1.350$ for $D B C$ was statistically significant with $P$ value, calculated at Mann-Whitney test, equal to 0.008 . This finding proves that SBC showed a better efficacy for cervical 
ripening than DBC (see Table 2). The calculated spontaneous vaginal delivery rate that happed earlier than the $24^{\text {th }}$ hour was $15.45 \%$ for SBC assisted labor and $8.18 \%$ for DBC assisted one with P values assessed after the statistical analysis $0.755 ; \chi 2=0.098$. The estimated spontaneous vaginal delivery time was $20.519 \pm 8.674$ hours for $S B C$ versus $27.069 \pm 12.817$ hours for $D B C$ with $P$ and $t$ values as follows: $0.013 ; 2.562$. As seen in Table 2 the SBC assisted childbirth demonstrated a shorter time from the balloon placement to the spontaneous delivery than the DBC one. Interestingly, almost the same number of patients from the two groups, respectively $46.36 \%$ for the SBC and $50.00 \%$ for the DBC could not initiate uterine contractions with the balloons. The calculated statistical parameters were as follows: $P=0.589$ and $2=0.291 .73 .64 \%$ versus $77.27 \%$ of the patients needed oxytocin for induction of labor after taking out of the balloon, proving that there were no significant differences between the two groups on this parameter (see Table 2). The spontaneous expulsion accounted for $17.27 \%$ and $13.64 \%$ within 24 hours in the single- and double-balloon groups, respectively with statistical parameters $\mathrm{P}=0.275$ and $\mathrm{x} 2=1.513$. The spontaneous expulsion time was $11.474 \pm 6.415$ and $11.385 \pm 6.212$ hours in the two groups, showing no significant difference between them. In terms of the cesarean section indications (Figure 3 and 4), our data showed that these indications were cephalopelvic disproportion calculated in $53.48 \%$ in SBC assisted childbirth and $47.82 \%$ in DBC one. The fetal distress was similar in both groups, i.e. $21.43 \%$ for SBC versus $23.91 \%$ for DBC. The failure to induced labor rate was $14.29 \%$ in SBC and $21.73 \%$ in the other group. There was no significant difference between the two groups (SBC vs $D B C)(P>0.05)$.

\subsection{Detected adverse reactions and complications}

We have observed that in the SBC group, due to adverse reactions in 12 of the cases the balloon was taken out halfway. This led to premature rupture of membranes in 8 cases, to massive vaginal bleeding in

2 of the cases, to intolerant discomfort in 1 case and to a single case with uterine tetanic contraction. The detected situation in the DBC group was as follows: in 4 cases the balloon was taken out and led to premature rupture of membranes. Data are shown in Table 3. There were statistically significant differences in the frequency of detected adverse reactions between the two groups with $P=0.041$ and $\chi 2$ $=4.157$. These results show that SBC demonstrated a higher incidence of adverse reactions than DBC. The incidence of the premature rupture of membranes was $7.27 \%$ in SBC group and $3.64 \%$ in the DBC one. Other detected complications included 1 case of cervical laceration and 1 case of umbilical cord prolapse that occurred in SBC group and 1 case of precipitate labor in DBC group. No postpartum hemorrhage, nor fever, nor uroschesis were detected in both groups.

\subsection{Amniotic fluid status and neonatal outcomes}

In the SBC group, Meconium-stained amniotic fluid (MSAF) accounted for $17.27 \%$ of the cases. In DBC group,Meconium-stained amniotic fluid $\ M S A F \bigvee a c c o u n t e d$ for $11.82 \%$. There was no significant difference in the amniotic fluid between the two groups $(P=0.38$; Mann-Whitney test).The results are given in Table 4. 
The incidence of neonatal Apgar score $\mathbb{7} \rrbracket 1$ minute after birth) was $97.27 \%$ versus $99.09 \%$. The incidence of neonatal Apgar score $\leq 7$ was $2.73 \%$ versus $0.91 \%$ and included 1 case with 6 points, 2 cases with 7 points in the single balloon group, and 1 case with 6 points in the double balloon group. There was no significant difference in the neonatal scores between the two groups $(P=0.627 ; \chi 2=0.236588)$. Results are shown in Table 4 . The fetal macrosomia $(\geq 4000 \mathrm{~g}$ ) was detected in 2 and 5 cases for SBC and DBC methods, respectively. These data show no significant difference in MSAF, in the neonatal Apgar score (1 minute) and in fetal macrosomia between the two groups.

\subsection{Statistical analysis of the parameter "primipara women" between the SBC and DBC groups}

Table 5 summarizes the statistical analysis of the parameter "first birth", i.e. the primipara women. The statistical analysis of this parameter between the two groups showed no significant difference in the delivery mode $(P=0.969 ; \chi 2=0.002)$. The cervical bishop score was $2.551 \pm 1.61$ in SBC against

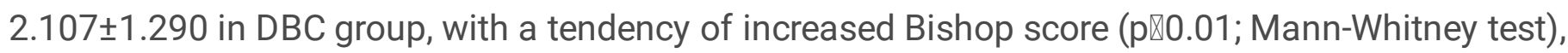
demonstrating better efficacy of SBC assisted childbirth in these women. The spontaneous vaginal delivery rates within less than 24 hours in the two groups of primipara women were similar. The statistical values were $P=0.522$ and $\chi 2=0.411$, while the spontaneous vaginal delivery time was 20.1888 . SBC demonstrated shorter time between the time from balloon placement to spontaneous delivery than DBC in the cohort of theprimipara women. We could not detect significant differences between the two groups of patients on parameters like lack of uterine contractions, oxytocin need in the period of time after 24 hours from balloon placement and balloon spontaneous expulsion. The values of all assessed statistical parameters were as follows $\mathrm{P}=0.402$ and $\chi 2=0.704, \mathrm{P}=0.768$ and $\chi 2=0.087$, and $\mathrm{P}=0.442$ and $\chi 2=0.59$, respectively. There were also no significant differences between the two groups in the studied cesarean section indications in the primipara women cohort with values of the statistical parameters as follows: $P=0.474$ and $\chi 2=1.491$ ). No statistically significant differences in the detected adverse reactions which caused the balloon to be removed halfway were calculated for this cohort of women between the two groups. The assessed statistical values were as follows $P=0.144$ and $\chi 2=2.13$. There was no significant difference in the incidence of the Meconium-stained amniotic fluid $\triangle \mathrm{MSAF}$ ), nor in the incidence of the neonatal Apgar score $(\leq 7)$ and in the fetal macrosomia $(\geq 4000 \mathrm{~g})$ between the two groups. The values of the statistical parameters confirmed this (see Table 5).

\subsection{Statistical analysis of the parameter "multipara women" between the SBC and DBC groups}

In the cohort of the multipara women, there was no statistically significant difference in the delivery mode between the two groups $(P=0.324 ; \chi 2=0.961)$. Data are presented in Table 6 . The mean cervical bishop score was calculated $6.810 \pm 1.816$ in the SBC group and $5.654 \pm 1.958$ in the DBC one. The mean increased Bishop score of the time after the removal of the balloon off the cervix or its natural falling off, was calculated as 3.619 \pm 2.061 against $2.115 \pm 1.558, p=0.03 ; p=0.011$; Mann-Whitney test it shows that SBC showed a better efficacy than DBC for cervical ripening in multipara women. The spontaneous vaginal delivery $<24$ hours and the spontaneous vaginal delivery time in the two groups were similar with estimated statistical values: $P=0.435$ and $x 2=0.611 ; p=0.616$ and $t=0.510$, respectively. There were no 
significant difference between the two groups in patients that could not initiate uterine contractions with the balloons, nor in those who needed oxytocin after 24 hours from the balloon placement and its spontaneous expulsion. The respective statistical values were calculated as follows $P=0.76$ and $x 2$ $=0.093 ; P=0.721$ and $\chi 2=0.127 ; P=0.459$ and $\chi 2=0.547$, and are shown in Table 6 . respectively. There were no statistically significant differences between the two groups in regard to the cesarean section indications in the cohort of the multipara women $(P=0.636)$. Moreover, no statistically significant differences were observed in the incidence of adverse reactions in this cohort and among the two groups. There was no significant difference in the incidence of the Meconium-stained amniotic fluid (MSAF) between the two groups $(P=0.485$ and $2=0.488)$. 1 case with neonatal Apgar score $\leq 7$ in the double balloon group was detected among the multipara women. Interestingly, no further complications were found among the patients from this cohort.

\subsection{Multivariate analysis of the cesarean section operation in the two groups of patients}

We have performed a multivariate analysis of the caesarian section rate between the two groups and results are shown in Table 7. In the SBC group, the single factor analysis showed that the spontaneous labor, the parity, and the cervical Bishop score after the removal or the expulsion of the balloon increased the Bishop score and among the groups the differences in its values were statistically significant, furthermore were associated with the decrease of the cesarean section rate with $P$ values $<0.05$. The multivariate analysis model showed that the spontaneous labor (HR:5.393 $₫ 95 \% \mathrm{Cl}: 1.389-20.945)$ could be used as an independent predict factor of the cesarean section. In the SBC group (Table 8), the single factor analysis showed that the Bishop score was associated with the cesarean section $(p=0.024)$.

\section{Discussion}

Cervical maturity is a decisive factor in the success of induced labor, as poor cervical conditions reduce the rate of vaginal delivery. Here, we have applied the cervical Bishop score to assess cervical maturity. The score with values $\geq 7$ indicated that the cervix is mature and the success rate of the trial birth is more than $80 \%$. Values of the Bishop score $\leq 6$ were accepted as indicators of immature cervix that frequently led to assisted labor through promotion of cervical maturation. No surprise that an important question for all obstetricians has been the problem with the quick ripening of the cervix in a safe and effective for the induced labor way. A major requirement to the perfect method for cervix ripening is to be safe for both the mother and the fetus, to be cost effective, to lead to slightest discomfort and to not require extensive monitoring (3). At present, there are many methods to ripen the cervix and to induce labor, including drug and mechanical materials, both proven effective (4)(5). The most commonly used drugs include oxytocin, dinoprostone suppositories, misoprostol and others. The oxytocin is the most classic drug of inducing labor as it dilates the cervix by stimulating the contraction of the smooth muscles of the uterus. Its effect is not only related to the concentration of the oxytocin, but also to the uterine state and the number of oxytocin receptors. Dinoprostone suppositories and misoprostol have good effect on softening of the cervix and inducing contractions. The dose of misoprostol is not easy to master as the effective dose varies greatly in different patients. Although PGE2 significantly reduces the rate of cesarean section, it 
has many disadvantages. At first, strong uterine contractions may cause uterine tonic contractions, fetal distress, placental abruption, acute labor, uterine rupture, postpartum hemorrhage, amniotic fluid embolism and other serious complications. Secondly, irregular uterine contractions also lead to poor tolerance of the patient. Next, theoretically PGE2 may lead to fever, vomiting, high blood pressure, diarrhea and asthma and other symptoms. Finally, the medical cares for such patients is a must, which increases the workload of medical staff (6).

Among the mechanical methods of inducing labor are the Foley catheter, the cervix balloon catheter, the seaweed rod and others. They are simple and safe, cost effective, mild and can be well controlled. The single balloon catheter (Foley) is the most commonly used mechanical method for inducing labor dating back to the 1960s and has been identified as a safe and effective method for mechanical induction of labor (7)(8). The original cervix double balloon was invented in 1991 by the American obstetriciangynecologist Atad (9). The cervical dilatation balloon is recommended in promoting cervical maturation and induced labor since 2009 by the American Society of Obstetricians and Gynecologists (ACOG) and is outlined in labor induction guidelines. It was officially recommended by the WHO guidelines for induced labor in 2011. In 2013, the U.S. Food and Drug Administration (FDA) officially approved the Cook cervical balloon and has declared that the COOK double cervical balloon has the same mechanism and efficacy with the Atad double balloon (10).

The mechanisms of action of the cervical balloon can be described as follows: (1) mechanical compression of the cervical canal; (2) the cervical decidual separation induces the synthesis and release of local endogenous prostaglandin in the cervix; (3) the so-called Ferguso effect, i.e. the balloon of water causes uterine cavity expansion, and the hypophysin and oxytocin release increase, causing uterine contractions and further cervical effacement and dilatation (11). The advantages of the cervix balloon catheter can be summarized as follows: (1) it is slow, mild and continuous for cervical maturation; (2) has less adverse reactions, allows free movement for patients; (3) the efficacy for inducing labor is good. It is especially recommended for patients and fetuses who cannot tolerate prolonged uterine contractions, such as women with uterine scarring, placental dysfunction, fetal growth restrictions and oligohydramnios. It is a good method to promote cervical maturation and induce labor, and is much safer than the use of drugs (12).

At present, two kinds of cervical balloon are commonly used in China and they are the single cervical balloon (love-baby), made by Jiangsu Aiyuan Technology Co and the COOK balloon, which is a double balloon made by COOK Technology Co. Both are made of silica gel. Although the mechanism of the two balloons is similar, they have differences in their design and features. The single balloon (love-baby) is a Chinese self-produced intrauterine balloon, and can inject $150 \mathrm{ml}$ of water and to expand to about 5-6 cm in diameter. It can also make the cervix to dilate up to $3-4 \mathrm{~cm}$. It is different from the single catheters in other countries, which generally are $16 \mathrm{~F}$ Foley catheters of 30-60 ml of water in the balloon. The COOK double balloon was imported and proved to be a very safe method for promoting cervix maturation abroad. It uses the $18 \mathrm{~F}$ catheter, with an intrauterine balloon and a vaginal balloon, both injected with 80 $\mathrm{ml}$ water. The mechanism of the COOK double balloon catheter includes a mechanical pressure on the 
cervix through the two balloons located in the inner and external part of the cervix. The mode of ripening of the cervix comes by the role of balloon compression. Due to the assistance of the vaginal balloon, the COOK double balloon is not easy to slip from the cervix, and the strength to the cervix is mild and continuous. In contrast, the single balloon (love-baby) with $150 \mathrm{ml}$ water in the balloon applies greater gravity on the cervix than the double balloon and dilate the cervix mainly by the role of gravity force.

Some authors believe that the increase in the volume of the balloon heavily increases the separation between the amniotic membrane and the uterine decidua, resulting in increased local secretion of prostaglandin and enhanced ability to promote cervical maturation. It is shown that $60 \mathrm{ml}$ or $80 \mathrm{~mL}$ of Foley single balloon catheters are more effective for inducing labor compared to $30 \mathrm{~mL}$ (13). Lin MG et al (14) found that the time from the induction of contractions to the child delivery assisted by the simple Foley balloon with water sac was shorter than that of the Foley balloon without a water sac, but there was no difference in the rate of cesarean section. Levy R (15) have found that ripening of the cervix with the larger balloon volume was associated with a significantly higher rate of dilatation of $3 \mathrm{~cm}$ or more. In primiparous women, the larger balloon volume can lead to a significantly higher rate of birth deliveries within 24 hours, and a significantly less requirements for use of oxytocin. Though other authors (16) have found that the Foley balloon with and without water sac has no difference in the induction of delivery interval, in the 24-hour vaginal delivery rate, and in the cesarean section rate.

Atad J (17) believes that the double balloon catheter has two balloons, thus giving greater compression to the cervix. However, Delaney S (18) showed that the COOK double balloon induced labor is not better than the $30 \mathrm{ml}$ of Foley single balloon catheter. Currently, most studies have found that the single and the double balloon catheters have similar efficiency, safety and patient satisfaction, but the single-balloon method is considered to be more cost-effective and is more easily accepted by patients $(12,19,15,20)$. Other authors (21) found that the mean intervention to the birth time, the vaginal delivery and the cesarean section rates, and maternal satisfaction were similar for both kind of balloons. Fang Yang (22) concluded that there was no significant difference in the estimated values for the cesarean section and vaginal delivery rate in 24 hours, nor in the average delivery time and improvement of Bishop score between the two groups. Raed Salim (23) found that the Length of time from balloon insertion to delivery, the incidence of the cesarean delivery had no statistically significant differences between the COOK double balloon and the single one without a difference among primiparous women. Furthermore, we have found that there was no significant difference in the vaginal delivery rate and the cesarean section rate between the two groups. The spontaneous vaginal delivery rate $<24$ hours from balloon placement were similar in the two groups. In addition to the rate of patients who needed oxytocin after removal of balloon was similar again with no statistical difference in two groups.

However, some scholars have confirmed that there are differences in the efficacy of the double balloon and the single balloon induced labor. Other authors (21) showed that there was a significant difference in the change of the Bishop score in the single balloon group compared with the double group, suggesting that the single balloon has a more significantly significant increase in the cervical Bishop score while Hoppe et al. (24) reported that among the cohort of primipara women, a greater proportion of the double 
balloon group achieved a Bishop score $\geq 6$ at the time of catheter removal and vaginally delivered labor compared to the single-balloon catheter assisted labor. No difference in the catheter type for achieving a Bishop score $\geq 6$ or vaginal delivery among multiparous women was detected, suggesting that the $80 \mathrm{~mL}$ double-balloon catheter is more effective than the $30 \mathrm{~mL}$ single-balloon catheter for pre-induction of cervical ripening and achieving a vaginal delivery in primipara. Mei-Dan E (25) found that although the success rates of cervical maturation between single and double balloon group is similar, the time from balloon insertion to expulsion and from insertion to delivery was significantly shorter in the simple balloon group compared with the double balloon group. Raed Salim (21) argues that the incidence of surgical delivery (forceps delivery or cesarean section) in the double balloon group was significantly higher than that in the simple group while Sayed Ahmed WA (26) found that balloon spontaneous expulsion rate in single balloon group happened more frequently than within the double balloon with a difference in the rate of up to $89.2 \%$. The time from balloon insertion to expulsion and from insertion to delivery was significantly shorter among the single balloon group. However, the median Bishop score was significantly higher when using the double balloon compared with the simple double balloon catheter after balloon removal. Pennell CE (20) also found that in the simple balloon group the time to delivery was shorter than the double balloon.

In our study, we have detected statistically significant difference in the cervical bishop score after removal or expulsion of the balloon and improved Bishop score between the two groups. The single cervix balloon group showed a better efficacy for cervical ripening, while the single cervix balloon showed shorter time from the balloon placement to spontaneous delivery than the double cervix balloon. We could not detect significant differences in the other parameters, such as the rate of patients that could not initiate uterine contractions, the oxytocin used mode of delivery, etc. We have also found that both in primipara and multipara cohorts of women the single balloon showed a better efficacy for cervical ripening. The single cervix balloon group showed shorter time between the balloon placement to the spontaneous delivery than in the double cervix balloon group in the primipara women, but not in multipara.

Although the balloon placement duration stated in the instructions was 12 hours, we found that it is too short to get a good efficacy for cervical ripening. Studies have concluded that it is safe to extend the placement time to 24 hours for pregnant women (27). Therefore in this study we have placed the cervical balloon for 24 hours. It is important the balloon to pass through the cervical canal and to be placed into the uterine cavity. In theory, there will be some complications such as uterine infection, premature rupture of membranes, cervical injury, umbilical cord prolapse and other conditions. In addition, the pressure and gravity action may cause discomfort to the patient. A recent systematic review suggests that mechanical methods reduced uterine hyperstimulation compared with PGE2 and misoprostol, but increased maternal and neonatal infectious morbidity compared with other methods(28). Limited data, though, from the Sciscione AC (29) Zieminska A (30) showed that there is no evidence that the cervical balloon catheter increases the risk of infection rates. Henry A (31) prove that the cervical balloon group had shorter hospital stay prior to birth and led to less pain and more sleep compared with vaginal PGE2. It is obvious that the outpatient balloon catheter ripening should be further investigated as an option for women (32). 
Jozwiak M (33) proved that the single balloon catheter had the lowest pain score with no increase in the risk for chorioamnionitis or endometritis.

Maslovitz S (34) retrospectively analyzed 1083 cases of women who had a placed balloon to promote cervical maturation and induced labor, which accounted for $7.8 \%$ of the women with complications, acute transient fever (3\%), pain (1.7\%), vaginal bleeding $(1.8 \%)$. The position of the fetus changed from head position to breech in $1.3 \%$ of the cases. Some authors state (30) that statistically the complications includes: $7.34 \%$ cases of premature rupture of the membranes (PROM), $10.09 \%$ cases were with a balloon which was taken out halfway due to pain and discomfort and $1.84 \%$ cases of bleeding. Salim R (23) concluded that there was no significant difference between the single and double balloon groups in the following aspects: maternal infection, postpartum hemorrhage, low Apgar score and NICU admission, placental abruption, uterine overstimulation, umbilical cord prolapse, infertility, Hoppe KK (24) found that there was no statistical difference in the incidence of post-delivery fever between the two groups, while Pennell CE (20) et al showed no significant difference in the incidence of postpartum hemorrhage in the two kinds of induced labor. However, other researchers have shown that the side effects in the two types of balloon were different. Cromi A (35) thinks the patient's discomfort in the single balloon is more obvious because gravity action, while Raed Salim (23) observed in the simple balloon group, adverse reactions which were significantly lower compared with double balloon group. Including fever and umbilical cord prolapse. In our study, we could not detect statistically significant differences in the detected adverse reactions. The single cervix balloon group had a higher incidence of such reactions than the double balloon group, including premature rupture of membranes, massive vaginal bleeding, intolerant discomfort and uterine tetanic contractions. Only 1 case of cervical laceration and 1 case of umbilical cord prolapse occurred in the single balloon group, while only 1 case of precipitated labor was detected in the double balloon group. There were no cases of postpartum hemorrhage, fever and uroschesis in the two groups.

\section{Conclusion}

Our results show that we are the first that report the efficacy and safety between this new single-balloon (lobe baby) and the COOK double-balloon in ripening the cervix and inducing labor. We have found that both the SBC and the DBC have equivalent efficacy in inducing labor, the new Chinese single balloon, also called love baby, can effectively induce labor as it may be highly recommendable for cervical ripening than DBC, though it could be with a higher incidence of adverse reactions causing the balloon to be pulled out halfway.

\section{Abbreviations}

SBC single cervix balloon catheter

DBC double cervix balloon catheter 
FGR fetal growth restriction

MSAF Meconium-stained amniotic fluid

PGE2 prostaglandin E2

ACOG American Society of Obstetricians and Gynecologists

FDA Food and Drug Administration

\section{Declarations}

\subsection{Ethics approval and consent to participate}

This study is a retrospective clinical study, which has no impact on patients' life safety and treatment plan, and will not lead to adverse consequences.Therefore, All patients gave informed consent,and oral consent was obtained from the Ethics Committee of the First Affiliated Hospital of Xi 'an Jiaotong University.

\subsection{Consent for publication}

All Authors Consent to publish this article.

\subsection{Availability of data and material}

All data in our article can be obtained from the medical record system of the First Affiliated Hospital of Xi 'an Jiaotong University.

\subsection{Competing interests}

There are no conflicts of interest.

\subsection{Funding}

There is no funding for this research.

\subsection{Authors' contributions}

all authors read and approved the final version of the manuscript

HM;(acquisition of data, or and drafting the article『;

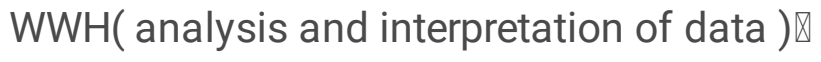

LD ( revising article )

$\mathrm{LXL}$ (conception and design,fnal approval of the version to be published) 


\subsection{Acknowledgement}

We gratefully acknowledge the invaluable contribution of Lixuelan,wang weihong ,Lidan in prepear this application note.

\section{References}

1. Osterman MJ, Martin JA. Recent declines in induction of labor by gestational age. NCHS Data Brief. 2014;(155):1-8.

2. Marroquin GA, Tudorica N, Salafia CM, Hecht R, Mikhail M. Induction of labor at 41 weeks of pregnancy among primiparas with an unfavorable Bishop score. Arch Gynecol Obstet. 2013;288(5):989-993.

3. Sciscione AC. Methods of cervical ripening and labor induction: mechanical. Clin Obstet Gynecol. 2014;57(2):369-376.

4. Bond DM, Gordon A, Hyett J, de Vries B, Carberry AE, Morris J. Planned early delivery versus expectant management of the term suspected compromised baby for improving outcomes. Cochrane Database Syst Rev. 2015;(11):CD009433. Published 2015 Nov 24. doi:10.1002/14651858.CD009433.pub2

5. Chen W, Xue J, Gaudet L, Walker M, Wen SW. Meta-analysis of Foley catheter plus misoprostol versus misoprostol alone for cervical ripening. Int J Gynaecol Obstet. 2015;129(3):193-198. doi:10.1016/j.ijgo.2015.01.005

6. Kelly AJ, Malik S, Smith L, Kavanagh J, Thomas J. Vaginal prostaglandin (PGE2 and PGF2a) for induction of labour at term. Cochrane Database Syst Rev. 2009;(4):CD003101. Published 2009 Oct 7. doi:10.1002/14651858.CD003101.pub2

7. Embrey MP, Mollison BG. The unfavourable cervix and induction of labour using a cervical balloon. $J$ Obstet Gynaecol Br Commonw. 1967;74(1):44-48. doi:10.1111/j.1471-0528.1967.tb03931.x

8. ACOG Committee on Practice Bulletins - Obstetrics. ACOG Practice Bulletin No. 107: Induction of labor. Obstet Gynecol. 2009;114(2 Pt 1):386-397.

9. Durie D, Lawal A, Zegelbone P. Other mechanical methods for pre-induction cervical ripening. Semin Perinatol. 2015;39(6):444-449. doi:10.1053/j.semperi.2015.07.006

10. Lim CE, Ng RW, Xu K. Non-hormonal methods for induction of labour. Curr Opin Obstet Gynecol. 2013;25(6):441-447. doi:10.1097/GC0.0000000000000027

11. Sciscione AC, Bedder CL, Hoffman MK, Ruhstaller K, Shlossman PA. The timing of adverse events with Foley catheter preinduction cervical ripening; implications for outpatient use. Am J Perinatol. 2014;31(9):781-786.

12. Pez V, Deruelle P, Kyheng M, Boyon C, Clouqueur E, Garabedian C. Méthodes de maturation cervicale et déclenchement du travail : évaluation de la sonde simple ballonnet comparée à la sonde double ballonnet et aux prostaglandines [Cervical ripening and labor induction: Evaluation of single balloon 
catheter compared to double balloon catheter and dinoprostone insert]. Gynecol Obstet Fertil Senol. 2018;46(7-8):570-574.

13. Kashanian M, Nazemi M, Malakzadegan A. Comparison of 30-mL and 80-mL Foley catheter balloons and oxytocin for preinduction cervical ripening. Int J Gynaecol Obstet. 2009;105(2):174-175. doi:10.1016/j.ijgo.2009.01.005

14. Lin MG, Reid KJ, Treaster MR, Nuthalapaty FS, Ramsey PS, Lu GC. Transcervical Foley catheter with and without extraamniotic saline infusion for labor induction: a randomized controlled trial. Obstet Gynecol. 2007;110(3):558-565. doi:10.1097/01.AOG.0000278077.30890.87

15. Levy R, Kanengiser B, Furman B, Ben Arie A, Brown D, Hagay ZJ. A randomized trial comparing a 30$\mathrm{mL}$ and an 80-mL Foley catheter balloon for preinduction cervical ripening. Am J Obstet Gynecol. 2004;191(5):1632-1636. doi:10.1016/j.ajog.2004.03.033

16. Guinn DA, Davies JK, Jones RO, Sullivan L, Wolf D. Labor induction in women with an unfavorable Bishop score: randomized controlled trial of intrauterine Foley catheter with concurrent oxytocin infusion versus Foley catheter with extra-amniotic saline infusion with concurrent oxytocin infusion. Am J Obstet Gynecol. 2004;191(1):225-229. doi:10.1016/j.ajog.2003.12.039

17. Atad J, Hallak M, Ben-David Y, Auslender R, Abramovici H. Ripening and dilatation of the unfavourable cervix for induction of labour by a double balloon device: experience with 250 cases. $\mathrm{Br}$ J Obstet Gynaecol. 1997;104(1):29-32. doi:10.1111/j.1471-0528.1997.tb10644.x

18. Delaney S, Shaffer BL, Cheng YW, et al. Labor induction with a Foley balloon inflated to $30 \mathrm{~mL}$ compared with $60 \mathrm{~mL}$ : a randomized controlled trial. Obstet Gynecol. 2010;115(6):1239-1245. doi:10.1097/AOG.0b013e3181dec6d0

19. Liu X, Wang Y, Zhang F, et al. Double- versus single-balloon catheters for labour induction and cervical ripening: a meta-analysis. BMC Pregnancy Childbirth. 2019;19(1):358. Published 2019 Oct 16. doi:10.1186/s12884-019-2491-4

20. Pennell CE, Henderson JJ, O'Neill MJ, McChlery S, Doherty DA, Dickinson JE. Induction of labour in nulliparous women with an unfavourable cervix: a randomised controlled trial comparing double and single balloon catheters and PGE2 gel [published correction appears in BJOG. 2011 Mar;118(4):521. McCleery, S [corrected to McChlery, S]]. BJOG. 2009;116(11):1443-1452. doi:10.1111/j.14710528.2009.02279.x

21. Lajusticia H, Martínez-Domínguez SJ, Pérez-Roncero GR, Chedraui P, Pérez-López FR; Health Outcomes and Systematic Analyses (HOUSSAY) Project. Single versus double-balloon catheters for the induction of labor of singleton pregnancies: a meta-analysis of randomized and quasirandomized controlled trials. Arch Gynecol Obstet. 2018;297(5):1089-1100.

22. Yang $F$, Huang $S$, Long $Y$, Huang L. Double-balloon versus single-balloon catheter for cervical ripening and labor induction: A systematic review and meta-analysis. J Obstet Gynaecol Res. 2018;44(1):2734. doi:10.1111/jog.13551

23. Salim R, Zafran N, Nachum Z, Garmi G, Kraiem N, Shalev E. Single-balloon compared with doubleballoon catheters for induction of labor: a randomized controlled trial. Obstet Gynecol.

Page 14/ 23 
2011;118(1):79-86. doi:10.1097/AOG.0b013e318220e4b7

24. Hoppe KK, Schiff MA, Peterson SE, Gravett MG. $30 \mathrm{~mL}$ Single- versus $80 \mathrm{~mL}$ double-balloon catheter for pre-induction cervical ripening: a randomized controlled trial. J Matern Fetal Neonatal Med. 2016;29(12):1919-1925. doi:10.3109/14767058.2015.1067297

25. Mei-Dan E, Walfisch A, Suarez-Easton S, Hallak M. Comparison of two mechanical devices for cervical ripening: a prospective quasi-randomized trial. J Matern Fetal Neonatal Med. 2012;25(6):723-727. doi:10.3109/14767058.2011.591459

26. Sayed Ahmed WA, Ibrahim ZM, Ashor OE, Mohamed ML, Ahmed MR, Elshahat AM. Use of the Foley catheter versus a double balloon cervical ripening catheter in pre-induction cervical ripening in postdate primigravidae. J Obstet Gynaecol Res. 2016;42(11):1489-1494. doi:10.1111/jog.13086

27. Ekele BA, Isah AY. Cervical ripening: how long can the Foley catheter safely remain in the cervical canal?. Afr J Reprod Health. 2002;6(3):98-102.

28. Mozurkewich EL, Chilimigras JL, Berman DR, et al. Methods of induction of labour: a systematic review. BMC Pregnancy Childbirth. 2011;11:84. Published 2011 Oct 27. doi:10.1186/1471-2393-1184

29. Sciscione AC, Bedder CL, Hoffman MK, Ruhstaller K, Shlossman PA. The timing of adverse events with Foley catheter preinduction cervical ripening; implications for outpatient use. Am J Perinatol. 2014;31(9):781-786.

30. Jagielska I, Kazdepka-Ziemińska A, Janicki R, Fórmaniak J, Walentowicz-Sadłecka M, Grabiec M. Ocena skuteczności i bezpieczeństwa preindukcji porodu cewnikiem Foley'a [Evaluation of the efficacy and safety of Foley catheter pre-induction of labor]. Ginekol Pol. 2013;84(3):180-185.

31. Henry A, Madan A, Reid R, et al. Outpatient Foley catheter versus inpatient prostaglandin E2 gel for induction of labour: a randomised trial. BMC Pregnancy Childbirth. 2013;13:25. Published 2013 Jan 29. doi:10.1186/1471-2393-13-25

32. Wilkinson C, Adelson P, Turnbull D. A comparison of inpatient with outpatient balloon catheter cervical ripening: a pilot randomized controlled trial. BMC Pregnancy Childbirth. 2015;15:126. Published 2015 May 28. doi:10.1186/s12884-015-0550-z

33. Jozwiak M, Bloemenkamp KW, Kelly AJ, Mol BW, Irion O, Boulvain M. Mechanical methods for induction of labour. Cochrane Database Syst Rev. 2012;(3):CD001233. Published 2012 Mar 14.

34. Maslovitz S, Lessing JB, Many A. Complications of trans-cervical Foley catheter for labor induction among 1,083 women. Arch Gynecol Obstet. 2010;281(3):473-477. doi:10.1007/s00404-009-1136-7

35. Cromi A, Ghezzi F, Tomera S, Uccella S, Lischetti B, Bolis PF. Cervical ripening with the Foley catheter. Int J Gynaecol Obstet. 2007;97(2):105-109. doi:10.1016/j.ijgo.2006.10.014

\section{Tables}


Table 1 Demographic data in the two groups

\begin{tabular}{llll}
\hline & single cervix balloon group $(\mathrm{n}=110)$ & double cervix balloon group $(\mathrm{n}=110)$ & $\mathbf{P}$ \\
\hline age (years old) & $28.736 \pm 3.639(28,20-41)$ & $29.355 \pm 3.598(29,21-42)$ & 0.257 \\
parity & & & 0.373 \\
$\quad$ primipara & $89(80.9 \%)$ & $84(77.27 \%)$ & \\
$\quad$ multipara & $21(19.1 \%)$ & $26(22.73 \%)$ & \\
gestational weeks & $39.838 \pm 1.053(40.071,37.429-41.714)$ & $40.066 \pm 1.061(40.214,37-42)$ & $\mathrm{P}=0.068$ \\
\hline
\end{tabular}

Table 2 delivery outcome and related obstetric parameters in the two groups

\begin{tabular}{|c|c|c|c|}
\hline & $\begin{array}{l}\text { single cervix belloon } g \\
\text { roup }(n=110)\end{array}$ & $\begin{array}{l}\text { double cervix balloon } g r \\
\text { oup }(n=110)\end{array}$ & $\mathbf{P}$ \\
\hline Delivery way & & & 0.68 \\
\hline Vaginal delivery & $67(60.9 \%)$ (1 forceps ) & $64(58.18 \%)$ (1 forceps ) & \\
\hline Cesarean section & $43(39.1 \%)$ & $46(41.82 \%)$ & \\
\hline \multicolumn{4}{|l|}{ Improvement of cervical score } \\
\hline before & $3.664 \pm 1.416(4,1-6)$ & $3.355 \pm 1.324(3,0-6)$ & 0.089 \\
\hline after & 6. $418 \pm 1.511(6,3-13)$ & 5. $473 \pm 1.618(5,2-10)$ & $<0.0001$ \\
\hline increased & 2. $755 \pm 1.746(3,0-8)$ & 2. $109 \pm 1.350(2,0-6)$ & 0.008 \\
\hline $\begin{array}{l}\text { Spontaneous delivery within } 24 \text { hours from } \\
\text { balloon placement }\end{array}$ & $17(15.45 \%)$ & $13(8.18 \%)$ & 0.755 \\
\hline $\begin{array}{l}\text { Spontaneous delivery time from balloon pl } \\
\text { acement (hours) }\end{array}$ & $20.519 \pm 8.674(22,7-34)$ & $27.069 \pm 12.817(27,3-57)$ & 0.013 \\
\hline $\begin{array}{l}\text { Cen not initiate uterine contractions wit } \\
\mathrm{h} \text { balloons }\end{array}$ & $51(46.36 \%)$ & $55(50 \%)$ & 0.589 \\
\hline $\begin{array}{l}\text { need use oxytocin after } 24 \text { hours from bal } \\
\text { loon placement }\end{array}$ & $81(73.64 \%)$ & $85(77.27 \%)$ & 0.396 \\
\hline $\begin{array}{l}\text { Balloon spontaneous expulsion within } 24 \mathrm{~h} \\
\text { ours from balloon placement }\end{array}$ & $19(17.27 \%)$ & $13(13.64 \%)$ & 0.275 \\
\hline $\begin{array}{l}\text { Balloon Spontaneous expulsion time } \\
\text { (hours) }\end{array}$ & $11.474 \pm 6.415(13,1-22)$ & 11. $385 \pm 6.212(11,2-20)$ & 0.969 \\
\hline
\end{tabular}


Table 3 Adverse reactions and complications.

\begin{tabular}{|c|c|c|c|}
\hline & $\begin{array}{l}\text { single cervix balloon group } \\
(n=110)\end{array}$ & $\begin{array}{l}\text { double cervix balloon group } \\
(n=110)\end{array}$ & $\mathbf{P}$ \\
\hline $\begin{array}{l}\text { Adverse reactions } \\
\text { (take out balloon halfway) }\end{array}$ & 12 & 4 & 0.041 \\
\hline premature rupture of membranes & $8(7.27 \%)$ & $4(3.64 \%)$ & 0.248 \\
\hline massive vaginal bleeding & 2 & 0 & \\
\hline Can't tolerate & $\begin{array}{l}1 \text { (Abdominal distension and } \\
\text { pain) }\end{array}$ & 0 & \\
\hline Uterine Tetanic contraction & 1 & 0 & \\
\hline complications & 2 & 1 & \\
\hline $\begin{array}{l}\text { precipitate labour } \\
\text { (<3h vaginal delivery) }\end{array}$ & 0 & 1 & \\
\hline Cervical laceration & 1 & 0 & \\
\hline Umbilical cord prolapse & 1 & & \\
\hline Postpertum hemorrhage & 0 & 0 & \\
\hline Pever & 0 & 0 & \\
\hline uroschesis & 0 & 0 & \\
\hline
\end{tabular}

Table 4 amniotic fluid status and Neonatal outcomes in two groups

\begin{tabular}{|c|c|c|c|}
\hline & $\begin{array}{l}\text { single cervix balloon group } \\
(n=110)\end{array}$ & $\begin{array}{l}\text { double cervix balloon group } \\
(n=110)\end{array}$ & $\mathbf{P}$ \\
\hline Clear amiotic fluid & $97(88.18 \%)$ & $90(81.82 \%)$ & 0.186 \\
\hline $\begin{array}{l}\text { Weconium-stained amniotic fluid } \\
\text { (USAP) }\end{array}$ & $13(11.82 \%)$ & $19(17.27 \%)$ & \multirow[t]{4}{*}{0.38} \\
\hline III• & $7(6.36 \%)$ & $16(14.55 \%)$ & \\
\hline $\mathrm{II}^{\bullet}$ & $5(4.55 \%)$ & $2(1.82 \%)$ & \\
\hline $\mathrm{I}^{\bullet}$ & $1(0.91 \%)$ & $1(0.91 \%)$ & \\
\hline $\begin{array}{l}\text { Neonatal Apgar score (1 minute a } \\
\text { fter birth) }\end{array}$ & & & \multirow[t]{3}{*}{0.627} \\
\hline$\leqslant 7$ & $3(2.73 \%)$ & $1(0.91 \%)$ & \\
\hline$>7$ & $107(97.27 \%)$ & $109(99.09 \%)$ & \\
\hline $\begin{array}{l}\text { fetal macrosomia } \\
(\geqslant 4000 \mathrm{~g})\end{array}$ & 2 & 5 & 0.442 \\
\hline
\end{tabular}




\begin{tabular}{|c|c|c|c|}
\hline & \multicolumn{2}{|l|}{ Primipere } & \multirow[b]{2}{*}{$\mathbf{P}$} \\
\hline & $\begin{array}{l}\text { single cervix } \\
\text { belloon group }(n=89)\end{array}$ & $\begin{array}{l}\text { double cervix } \\
\text { belloon group }(n=84)\end{array}$ & \\
\hline Delivery ray & & & 0.969 \\
\hline Vaginal delivery & $49(55.0 \%)$ & $46(54.8 \%)$ & \\
\hline Cosarean section & $40(45.0 \%)$ & $38(45.2 \%)$ & \\
\hline \multicolumn{4}{|l|}{ corvical score } \\
\hline before & 3. $775 \pm 1.371(4,1-6)$ & $3.598 \pm 1.404(3,0-6)$ & 0.076 \\
\hline after & $6.326 \pm 1.428(6,3-10)$ & $5.417 \pm 1.507(5,2-10)$ & 0.091 \\
\hline Increased & $2.551 \pm 1.61(2,0-7)$ & 2. $107 \pm 1.290(2,0-6)$ & $<0.001$ \\
\hline $\begin{array}{l}\text { Spontaneous delivery within } 24 \text { hours from b } \\
\text { alloon placement }\end{array}$ & 10 (11. 23\%) & $7(8.33 \%)$ & 0.522 \\
\hline $\begin{array}{l}\text { Spontaneous delivery time from balloon plac } \\
\text { emont (bours) }\end{array}$ & 20. $188 \pm 7.943(22,8-32)$ & $32.870 \pm 15.104(30,3-72)$ & 0.005 \\
\hline $\begin{array}{l}\text { Can not initiate uterine contractions with } \\
\text { belloons }\end{array}$ & $42(47.19 \%)$ & $45(53.57 \%)$ & 0.402 \\
\hline $\begin{array}{l}\text { need use oxytocin after } 24 \text { hours from ballo } \\
\text { on placemont }\end{array}$ & $65(73.03 \%)$ & $63(75 \%)$ & 0.768 \\
\hline $\begin{array}{l}\text { Balloon Spontaneous expulsion within } 24 \text { hou } \\
\text { rs from balloon placement }\end{array}$ & $13(14.6 \%)$ & $9(10.7 \%)$ & 0.442 \\
\hline Belloon spontaneous expulsion time (hours) & $12.154 \pm 5.550(14,1-20)$ & 12. $111 \pm 5.231(11,3-20)$ & 0.986 \\
\hline Indications of cosarean section & & & 0.474 \\
\hline cephelopelvic disproportion & $22(55.0 \%)$ & $18(47.37 \%)$ & \\
\hline fetal distress & $7(17.5)$ & $9(23.68 \%)$ & \\
\hline Fallure to induced labor & $6(15 \%)$ & $9(23.68 \%)$ & \\
\hline $\begin{array}{l}\text { Adverse reactions (take out balloon halfira } \\
\text { y) }\end{array}$ & 8 & 3 & 0.144 \\
\hline premature rupture of membranes & 5 & 3 & 0.781 \\
\hline massive raginal bleoding & 1 & 0 & \\
\hline Can't tolerate & 1 & 0 & \\
\hline Uterine Tetanic contraction & 1 & 0 & \\
\hline complications & 2 & 1 & \\
\hline precipitate labour ( $<3$ h vaginal delivery) & 0 & 1 & \\
\hline Cervical laceration & 1 & 0 & \\
\hline Unbilical cord prolapse & 1 & 0 & \\
\hline Fever & 0 & 0 & \\
\hline Weconiur-stained amiotic fluid (USAP) & $12(13.5 \%)$ & $15(17.95)$ & 0.408 \\
\hline $\begin{array}{l}\text { Neonatal Apgar score (1 minute after birth) } \\
\leqslant 7\end{array}$ & 3 & 0 & 0.261 \\
\hline fotal macrosonis $(\geqslant 4000 \mathrm{~g})$ & 2 & 5 & 0.395 \\
\hline
\end{tabular}


table 6 Demographic data of multipara in two groups.

\begin{tabular}{|c|c|c|c|}
\hline & $\begin{array}{l}\text { Multipera } \\
\text { single cervix balloon gr } \\
\text { oup ( } n=21)\end{array}$ & $\begin{array}{l}\text { double cervix belloon } \\
\text { group }(n=26)\end{array}$ & $\mathrm{P}$ \\
\hline Delivery may & & & 0.324 \\
\hline Vaginal delivery & $18(85.7 \%)$ & $18(69.2 \%)$ & \\
\hline $\begin{array}{l}\text { Cosarean section } \\
\text { cervical score }\end{array}$ & $3(14.3 \%)$ & $8(30.8 \%)$ & \\
\hline before & $3.190 \pm 1.537(3,1-6)$ & $3.538 \pm 1.029(4,1-5)$ & 0. 387 \\
\hline after & $6.810 \pm 1.816(7,4-13)$ & $5.654 \pm 1.958(5.5,2-10)$ & 0.03 \\
\hline Increase & $3.619 \pm 2.061(3,1-8)$ & 2. $115 \pm 1.558(2,0-6)$ & 0.011 \\
\hline $\begin{array}{l}\text { Spontaneous delivery within } 24 \text { hours fr } \\
\text { on belloon placement }\end{array}$ & $7(33.33 \%)$ & $6(23.08 \%)$ & 0.435 \\
\hline $\begin{array}{l}\text { Spontaneous delivery timo from balloon } \\
\text { placement (hours) }\end{array}$ & $21 \pm 9.990(22,7-34)$ & 18. $778 \pm 9.324(23,3-29)$ & 0.616 \\
\hline $\begin{array}{l}\text { Can not initiate uterine contractions " } \\
\text { ith belloons }\end{array}$ & $9(42.86 \%)$ & $10(38.46 \%)$ & 0.76 \\
\hline $\begin{array}{l}\text { need use oxytocin after } 24 \text { hours from b } \\
\text { alloon placement }\end{array}$ & $16(76.19 \%)$ & $22(84.62 \%)$ & 0.721 \\
\hline $\begin{array}{l}\text { Balloons apontaneous expulsion within } 2 \\
4 \text { hours from balloon placemont }\end{array}$ & $6(28.6 \%)$ & $4(15.4 \%)$ & 0.459 \\
\hline $\begin{array}{l}\text { Balloons spontaneous expulsion time } \\
\text { (hours) }\end{array}$ & $10 \pm 8.390(8,2-22)$ & 9. $75 \pm 8.732(8.5,2-20)$ & 0.965 \\
\hline Indications of cosarean section & & & 0.636 \\
\hline cephalopelvic disproportion & 1 & 4 & \\
\hline fetal distress & 2 & 2 & \\
\hline Failure to induced labor & 0 & 1 & \\
\hline Adverse reections & 4 & 1 & 0.228 \\
\hline premature rupture of membranes & 3 & 1 & 0.454 \\
\hline massive raginal bleoding & 1 & 0 & \\
\hline Can't tolerate & 0 & 0 & \\
\hline Uterine Tetanic contraction & 0 & 0 & \\
\hline complications & 0 & 0 & \\
\hline $\begin{array}{l}\text { precipitate labour (<3h raginal delive } \\
\text { ry) }\end{array}$ & 0 & 0 & \\
\hline Cervical laceration & 0 & 0 & \\
\hline Unbilical cord prolapse & 0 & 0 & \\
\hline Pever & 0 & 0 & \\
\hline Weconiur-stained amiotic fluid (USAP) & $1(13.5 \%)$ & $4(17.9 \%)$ & 0.485 \\
\hline $\begin{array}{l}\text { Neonatal Apgar score (1 minute after b1 } \\
r t b) \leqslant 7\end{array}$ & 0 & 1 & \\
\hline fotal macrosomis $(\geqslant 4000 \mathrm{~g})$ & 0 & 0 & \\
\hline
\end{tabular}




\begin{tabular}{|c|c|c|c|c|c|c|c|}
\hline & \multicolumn{4}{|c|}{ single factor analysis } & \multicolumn{3}{|c|}{ multiple-factor analysis } \\
\hline & Cesarean section & Vaginal delivery & $P$ & $\times 2$ & $P$ & OR & 0.95 of OR \\
\hline Spontaneous & & & & & & & \\
\hline labour & & & & & & & \\
\hline Yes & 4 & 26 & $<0.001$ & 13. 668 & 0.015 & 5. 393 & 1. $389-20.945$ \\
\hline no & 40 & 42 & & & & & \\
\hline Parity & & & & & & & \\
\hline primipara & 41 & 50 & 0.01 & 6. 707 & 0.051 & 0.256 & $0.065-1.006$ \\
\hline multipara & 3 & 18 & & & & & \\
\hline $\begin{array}{l}\text { Balloon Spontaneous } \\
\text { expulsion }\end{array}$ & & & & & - & - & - \\
\hline Yes & 5 & 14 & 0.21 & 1. 574 & & & \\
\hline no & 39 & 54 & & & & & \\
\hline age (years) & $\begin{array}{l}28.209 \pm 3.709(28 \\
20-38)\end{array}$ & $\begin{array}{l}29.075 \pm 3.077(28, \\
21-41)\end{array}$ & 0.28 & - & - & - & - \\
\hline gestational weeks & $\begin{array}{l}40.020 \\
1.092(40.286 \\
37.429-41.714)\end{array}$ & $\begin{array}{l}39.721 \\
1.019(39.714 \\
37.571-41.429)\end{array}$ & 0.109 & - & - & - & - \\
\hline $\begin{array}{l}\text { Bitshop score befo } \\
\text { re (points) }\end{array}$ & $\begin{array}{l}\text { 3. } 953 \pm 1.308(4, \\
1-6)\end{array}$ & $3.478 \pm 1.460(3,1-6)$ & 0.0782 & - & - & - & - \\
\hline $\begin{array}{l}\text { Bitshop score afte } \\
\text { r (points) }\end{array}$ & $\begin{array}{l}6.00 \pm 1.215 \quad(6, \\
3-8)\end{array}$ & $\begin{array}{l}6.687 \pm 1.626(7, \\
4-13)\end{array}$ & 0.032 & - & 0.977 & - & - \\
\hline $\begin{array}{l}\text { Developed Bitshop } \\
\text { score }\end{array}$ & $\begin{array}{l}\text { 2. } 047 \pm 1.379 \\
(2,0-5)\end{array}$ & 3. $209 \pm 1.813(3,0-8)$ & 0.001 & - & 0.086 & - & - \\
\hline
\end{tabular}

Table 8 Multivariate analysis of cesarean section operation in DBC group

\begin{tabular}{|c|c|c|c|c|c|c|c|}
\hline & \multicolumn{4}{|c|}{ single factor analysis } & \multicolumn{3}{|c|}{ multiple-factor analysis } \\
\hline & Cesarean section & Vaginal delivery & $P$ & $\times 2$ & $P$ & $\mathrm{OR}$ & 0.95 of $\mathrm{OR}$ \\
\hline $\begin{array}{l}\text { Spontaneous } \\
\text { labour } \\
\text { Yes } \\
\text { no }\end{array}$ & $\begin{array}{l}8(17.4 \%) \\
38(82.6 \%)\end{array}$ & $\begin{array}{l}18(28.1 \%) \\
46(71.9 \%)\end{array}$ & 0.191 & 1. 708 & - & - & - \\
\hline $\begin{array}{l}\text { Parity } \\
\qquad \begin{array}{l}\text { primipara } \\
\text { multipara2 }\end{array} \\
\end{array}$ & $\begin{array}{l}38(82.6 \%) \\
8(17.4 \%)\end{array}$ & $\begin{array}{l}46(71.9 \%) \\
18(28.1 \%)\end{array}$ & 0.191 & 1. 708 & - & - & - \\
\hline $\begin{array}{l}\text { Balloon Spontaneous } \\
\text { expulsion } \\
\text { Yes } \\
\text { no } \\
\text { age (years) }\end{array}$ & $\begin{array}{l}3(6.5 \%) \\
43(93.5 \%) \\
29.422 \pm 3.258 \\
(29,21-36)\end{array}$ & $\begin{array}{l}10(15.6 \%) \\
54(84.4 \%) \\
29.297 \pm 3.870 \quad(29 \\
24-42)\end{array}$ & 0.145 & 2. 128 & - & - & - \\
\hline $\begin{array}{l}\text { gestational weeks } \\
\text { Bitshop score bef } \\
\text { ore (points) }\end{array}$ & $\begin{array}{l}40.048 \pm 1.166(40.429 \\
37.142-42) \\
3.178 \pm 1.302(3,0-6)\end{array}$ & $\begin{array}{r}40.096 \pm 0.990 \\
(40.214,37-41.571) \\
3.453 \pm 1.332(4,1-6)\end{array}$ & 0.728 & - & - & - & - \\
\hline $\begin{array}{l}\text { Bitshop score aft } \\
\text { er (points) }\end{array}$ & 5. $133 \pm 1.517(5,2-10)$ & $\begin{array}{l}5.179 \pm 1.667 \quad(6, \\
2-10)\end{array}$ & 0.024 & - & - & - & - \\
\hline $\begin{array}{l}\text { Developed Bitshop } \\
\text { score } \\
\text { (95\%CI) }\end{array}$ & $1.956 \pm 1.313(2,0-6)$ & $\begin{array}{l}2.25 \pm 1.357 \quad(2, \\
0-61.894-2.598)\end{array}$ & 0.226 & - & - & - & - \\
\hline
\end{tabular}


Figures

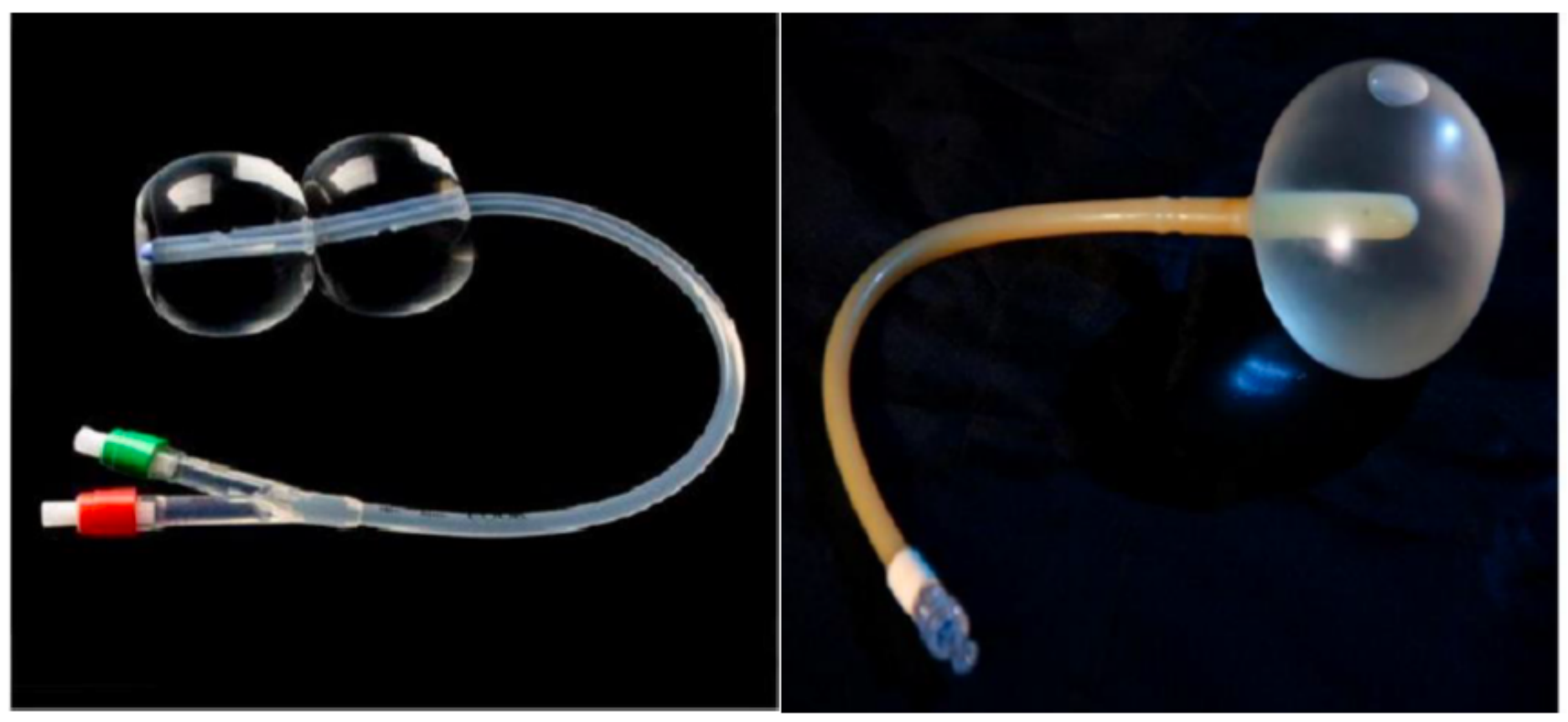

Figure 1

two types of cervical balloon 

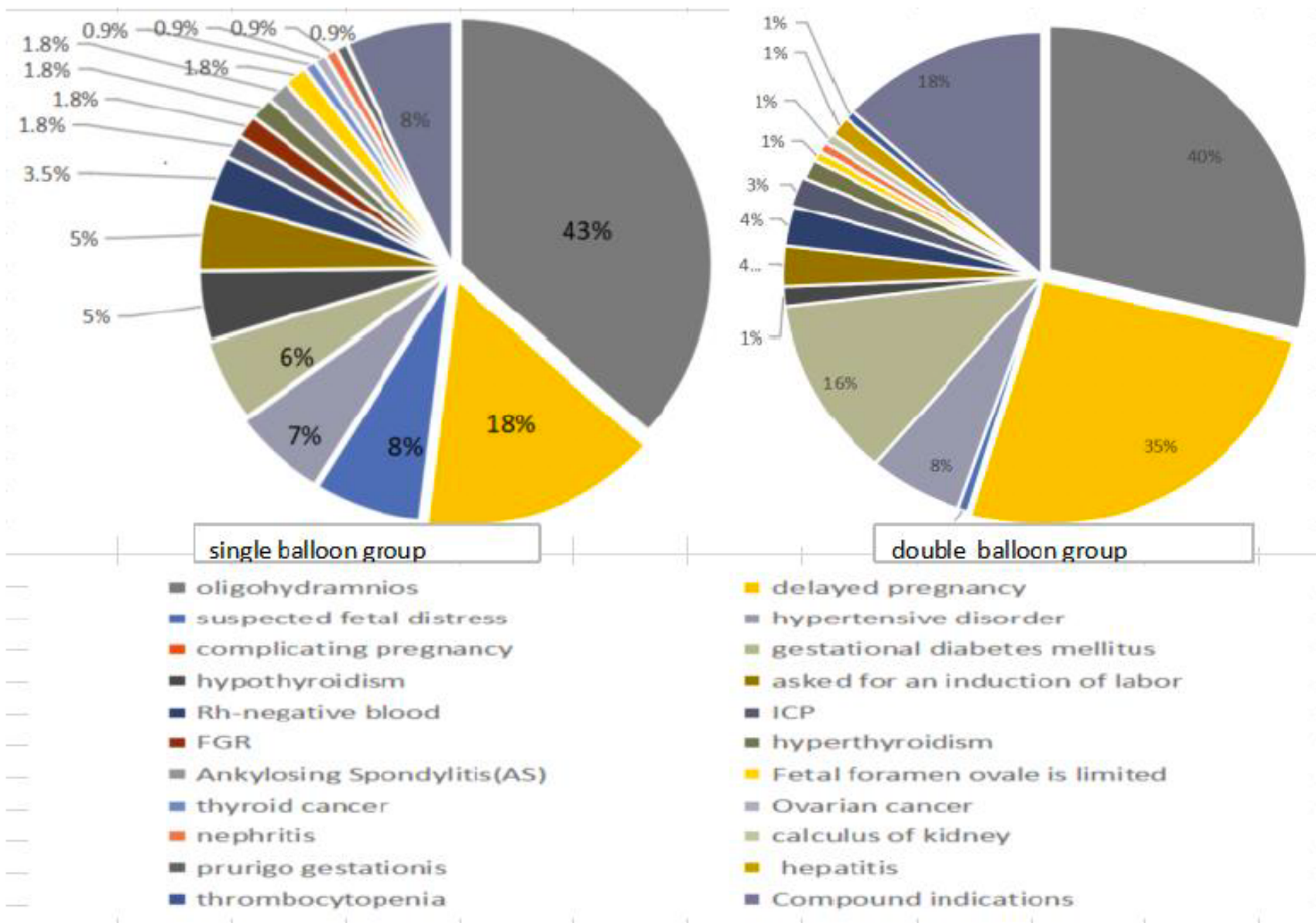

= delayed pregnancy

= hypertensive disorder

- gestational diabetes mellitus

- asked for an induction of labor

= ICP

- hyperthyroidism

- Fetal foramen ovale is limited

- Ovarian cancer

= calculus of kidney

nepatitis

- Compound indications

Figure 2

The indications of induced labor in the two groups

\section{single balloon group}

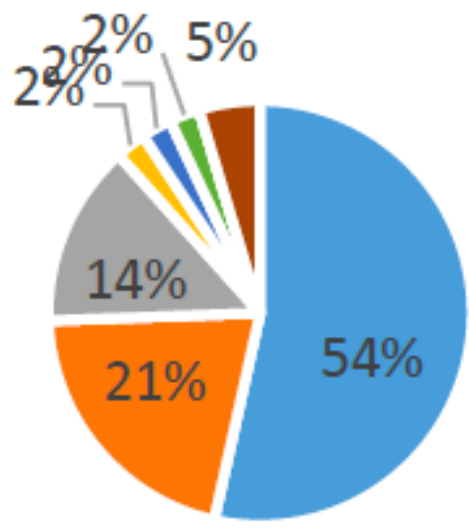

- cephalopelvic disproportion

- fetal distress

- Unsuccessfully induced labor 
Figure 3

indications of cesarean section in SBC group

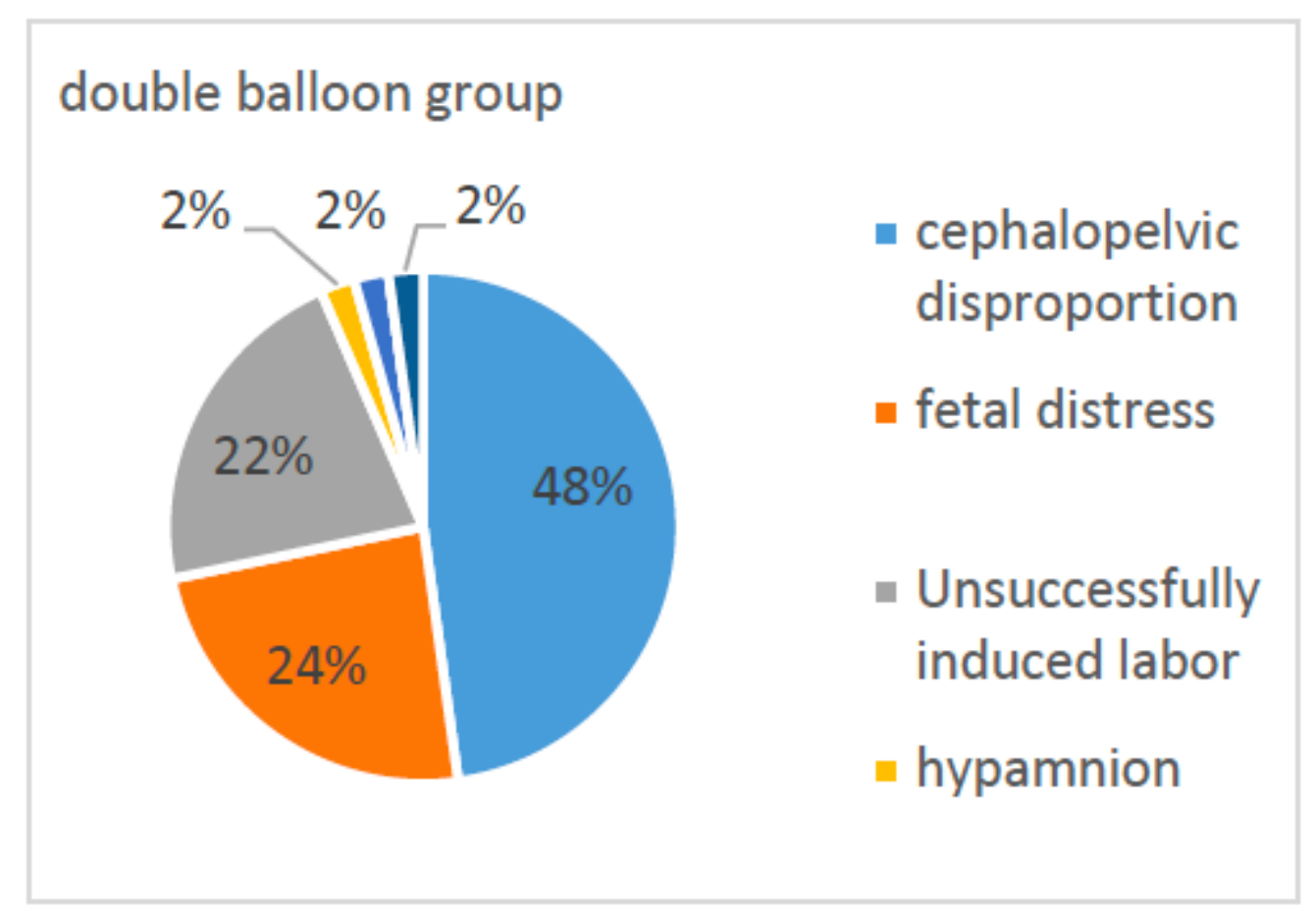

Figure 4

indications of cesarean section in DBC group 